\title{
The Effects of Kinesio Taping on the Lower-Body Injury Rehabilitation in Female Futsal Athletes
}

\author{
Alimin Hamzah*, Berliana Berliana, Pipit Pitriani, Mesianna Simbolon, Desmi Sartika, Puji Astuti \\ School of Postgraduate Studies, Faculty of Sport and Health Education \\ Universitas Pendidikan Indonesia \\ Bandung, Indonesia \\ *aliminhamzah@upi.edu
}

\begin{abstract}
In recent years, futsal is one of the most popular sports. The injuries that are often experienced by female futsal athletes involve the lower body. This paper presents scientific knowledge about the use of Kinesio Taping in futsal athletes who have suffered injuries, both during training and competing. In this study, a systematic review is used by reviewing several related articles of Kinesio Taping. This kinesio taping is made of cotton with acrylic adhesives that are patterned like human fingerprints, so that it matches the surface of the skin with an estimated usage of Kinesio Taping is 20-35 minutes. The nature of this Kinesio Taping is elastic which is able to stretch from $30 \%$ to $40 \%$ of its basic length resulting in convolution in the surface layer of the skin, which will lift the surface of the skin so that it can accelerate blood circulation and improve lymphatic circulation. Therefore, we suggest that Trainers and athletes should know the positive effects of using Kinesio Taping and how to use it, thus the results are more leverage.
\end{abstract}

\section{Keywords: Kinesio Taping, futsal, injury, female athletes}

\section{INTRODUCTION}

In recent years, futsal is a very popular sport, as stated by Ribeiro and Costa that futsal has attracted the attention of many people from young to old age. Its development is so rapid, and almost touches all levels of society in all corners of the world without exception in the archipelago [1]. Seeing the origin of this sport, futsal came from Uruguay precisely in Montevideo in 1930, by Juan Carlos Ceriani at the time of the biggest sporting event namely the world cup held in the country [2].

Futsal is also loaded with the probability of injury, in futsal sports, the incidence of injury is 55.2 per 10,000 hours and is included in the category of 10 sports with high injury rates [3]. As for the types of injuries in this sport according to Astrid Junge and Dvorak, there are 2 bruises (44.2\%) and sprains $(19.4 \%)$ are injuries that often occur and infect elite athletes in futsal. The probability of injury in Futsal sports is also greater than in football which is at a glance almost the same from the characters of the two sports [4]. This is consistent with what was stated by A. Junge and Devorak that futsal sports are around 2.7 times more than soccer which has a trauma injury grade of 2.3 [4].

The part of the body that is often injured is the lower body. As reported by Stracciolini states that excessive sports-related injuries of about two-thirds occur in the lower extremities [5].
More specifically injuries often occur in the ACL section, as reported by Maetzel, Krahn, \& Naglie helped to agree by stating the higher prevalence of ACL injuries in female athletes [6]. For female athletes, the probability of injury grade is higher compared to male athletes. Maetzel also report that stating the higher prevalence of ACL injuries in athletes' woman [6].

As discussed above ACL injuries, which the part of the body that often suffers injuries in futsal is the lower body. In the leg and calf area, we can find tibia stress syndrome and other frequently injured areas are the Achilles tendon [7]. The results of this study were also reinforced by de Vos who found in their study that up to $52 \%$ of runners (athletes) suffered injuries to their Achilles tendons and sometimes the effects lasted even long-term during their careers [8].

One of the solutive methods for overcoming injury problems in sports is the Kinesio taping method. Kase reported that Kinesio Taping can be used in any phase of injury whether it is acute, subacute or chronic, and can be combined with other types of therapy [9]. This method is not new, a lot of research has been done in an effort to investigate this method and the benefits obtained are also very significant. Such as research explained that in the event of damage to the musculoskeletal system [10]. Kinesio taping has the potential to reduce the effects of the pain. Another thing is, it can positively influence the perception of muscle fatigue [11].

\section{METHOD}

The systematic review in this paper follows the PRISMA guidelines [12].

\section{A. Injury in Female Athletes}

Injuries often occur in body contact athletes and the probability of injury to female athletes with different male athletes where female athletes are more likely to suffer injuries than male athletes. Data shows that the age range $<25$ years often has injuries involved in high school, collegiate, or league sports [13].

ACL size can also play a role in its ability to withstand pressure, in this case, the size of a woman's ACL is thinner than a man's. This is due to differences in hormones between men and women, they do not face the same risk. Therefore, female athletes have a higher probability of ACL injury. 
to regenerate [9]. As for Kase [18] some of the benefits of Kinesio Taping depend on the percentage of stretching and the direction of pulling from the Kinesio Taping. There are benefits of Kinesio Taping such as providing sensory stimulation to (1) provide positional stimulus, (2) create more space by lifting soft tissue, fascia and skin structure, (3) helping or limiting the range of motion, (4) aligning fascial tissue to reduce adhesion, and (5) reduce swelling and edema by inflammation directly leading to the lymphatic channel. Kinesio Taping effectively increases the alignment of body posture so that it is very compatible with the anatomy of a woman's body which is certainly different from that of men so that the probability of injury between the two is also different.

\section{Techniques for Using Kinesio Taping}

The inventor of Kinesio Taping is Dr. Kenzo Kase, revealed that Kinesio Taping can be used in several phases of injury, such as acute, subacute or chronic injury. Not only that, but Kase also explained that Kinesio Taping can be combined with other types of therapy. After experiencing many developments from its initial concept in 1973, Kinesio Taping underwent many modifications to its progress, and Kase has developed 6 Corrective application techniques such as mechanical, fascial, spatial, ligament/tendon, functional and lymphatic. Curative or preventive efforts have entered a new phase in which the treatment given is in accordance with the procedure of conformance to the problems encountered. For example, as stated by Kase [9] below:

- Mechanical correction techniques are said to be able to provide position stimulation through the skin that has been applied to Taping.

- Correction technique is to place the tissue in the desired position and provide stimulation to the body that will adjust the position to minimize the tension created by Kinesio Taping or limit joint movement.

- Refreshing blood as needed and improving lymph circulation resulting in a reduced amount of inflammatory substances.

- Reducing excessive irritation and optimizing stimulation of certain receptors (free nerve endings, Valter-Pacini and Ruffini corpuscles) followed by an appropriate response in the central nervous system by reducing pain and accelerating healing of damaged parts of the musculoskeletal system.

- Required stimulation of certain receptors and correct correction of joint function, so that it will cause positive modifications of the formula of motion with a better range of motion and increased joint stability.

- Kinesio Taping optimizes the athlete's "soul".

How to use the Kinesio Taping Method is by sticking to the skin for 20-30 minutes and this Kinesio taping can be used for several days. Before being placed on the surface of the skin, Kinesio Taping is stretched for stretching, because Kinesio Taping can stretch between $40 \%$ to $60 \%$ of its normal length, and it is the same as human skin's ability to stretch. For the estimated duration of its use, Kinesio Taping is recommended to be used for 24 - 48 hours rest in the damaged area to be able
- The fascia correction technique utilizes the Kinesio Taping "recoil effect" to break the boundaries of fascial movements through a combination of skin movements and the elastic properties of the Kinesio Taping. In this technique, Kinesio Taping is used by gentle oscillations such as micro-massage in order to break down the fascial fibres so that the muscles will straighten out in a more organized position.

- The space correction technique is basically the original concept of Kinesio Taping. This technique also utilizes the "recoil effect", ie interstitial space increases so that pain, inflammation, swelling, and edema can be overcome by using Kinesio Taping. Kase et al [9] also stated that this technique affects the stimulation of chemoreceptors, mechanoreceptors, and nociceptors which also contribute to pain relief.

- Ligament and tendon correction techniques aim to increase the stimulation of muscle tissue that is stimulated. As for tendon correction, the aim is to increase the stimulation of the Golgi tendon organ to stimulate the central nervous system to feel the tension in normal tissue. 
- Functional correction techniques are used as sensory stimuli to help or limit motion. KT is applied in such a way that the tension is removed during active movement. It is believed that the tension caused by increased stimulation during active movements will stimulate mechanoreceptors, thereby affecting motion.

- Circulation and lymphatic correction techniques are applied so that it pulls the direction of the exudate to the area with lower congestion. These techniques are similar to space correction techniques but differ in that their application is intended to guide lymphatic drainage away from the affected area in a particular direction, such as pulling swelling of the ankle sprain from distal to proximal.is used to format your paper and style the text. All margins, column widths, line spaces, and text fonts are prescribed; please do not alter.

The Kinesio Taping Lever also has a different shape, depending on the type. Among them are as follows [19]:

- "I" tape - usually used during the acute phase of pain or inflammation, and this type is most easily made.

- "Y" tape - usually used after the acute phase ends instead of the "I" band, so in this type one end is cut into two like "Y"

- "X" tape - usually used to carry tension which is better transferred to both ends, this type is almost the same as type "Y" but both ends are equally cut in two.

- "Fan" - usually used because of its ability to accelerate lymph flow,

- "Web" - suitable for maintaining large connections because of its large surface,

- "Donut hole" - usually used to reduce pressure in a damaged area, with a hole in the middle, used for bone spurs,

- "Star" - made by passing more "I" or "donut hole" tapes to increase the weight loss effect pressure in the centre of the "star".

Therefore the use of Kinesio Taping cannot be carelessly used, the level of injury and the location of the injury requires different treatment so that the results obtained are more optimal.

\section{CONCLUSION}

Recent research on Kinesio Taping shows that Kinesio Taping can reduce the pain suffered by futsal athletes. Especially injuries in futsal often occur in the lower body such as musculoskeletal and ACL where Kinesio Taping can suppress the pain. Kinesio Taping can be curative and preventive, if an athlete is in a condition of playing/competing and has an injury then Kinesio Taping can be used to suppress the pain that arises and restore the confidence of the athlete to continue playing. Therefore, knowledge about using Kinesio Taping is very important to be known by coaches and athletes. Coaches and athletes must be familiar with the use of Kinesio Taping when unexpected things happen such as suffering an injury during competition or training. In several studies on Kinesio Taping show the benefits of Kinesio Taping, such as can reduce pain during exercise. However, it is also undeniable that the effect of some Kinesio Taping is the placebo effect. That is due to already have a dependency on the tools namely Kinesio Taping so that athletes do not have confidence when exercising and do not use Kinesio Taping. However, outside of these controversies physiologically Kinesio Taping can overcome injuries suffered by futsal athlete. Suggest to the coach to understand the use of Kinesio Taping then the duration of use of Kinesio Taping and the combination of Kinesio Taping types used.

\section{ACKNOWLEDGMENT}

We would like to thank Dr. Berliana and Pipit Pitriani, $\mathrm{Ph} . \mathrm{D}$ because they have helped a lot in this research.

\section{REFERENCES}

[1] R. N. Ribeiro, and L.O.P. Costa, "Epidemiologic analysis of injuries occurred during the $15^{\text {th }}$ Brazilian Indoor Soccer (Futsal) Sub20 Team Selection Championship," Revista Brasileira de Medicina do Esporte, vol. 12(1), pp. 1-5, 2006.

[2] A. Jaya, "Futsal Gaya Hidup, Peraturan, dan Tips-Tips Permainan," Yogyakarta: Pustaka Timur, 2008

[3] S.L. Schmikli, F.J.G. Backx, H.J. Kemler, "National Survey on Sports Injuries in the Netherlands: Target Populations for Sports Injury Prevention Programs," Clin J Sport Med, vol. 19, pp. 101-106, 2009.

[4] A. Junge, and J. Dvorak, "Injury risk of playing football in Futsal World Cups,” British Journal of Sports Medicine, vol. 44(15), pp. 1089-1092, 2010 .

[5] A. Stracciolini, R. Casciano, H.L. Friedman, W.P. Meehan 3rd, L.J. Micheli, "A closer look at overuse injuries in the pediatric athlete," Clin J Sports Med, vol. 25(1), pp. 30-35, 2015.

[6] A. Maetzel, M. Krahn, and G. Naglie, "The cost effectiveness of rofecoxib and celecoxib in patients with osteoarthritis or rheumatoid arthritis," Arthritis Rheum, vol. 49(3), pp. 283-292, 2003.

[7] H. Alfredson, "Chronic midportion Achilles tendinopathy: an update on research and treatment. Clinical Journal of Sport Medicine, vol. 22(4), pp. 727-741, 2003.

[8] R.J. De Vos, A. Weir, H.T.M. van Schie, "Platelet-rich plasma injection for chronic Achilles tendinopathy - a randomized controlled trial," The Journal of American Medical Association, vol. 303(2), pp. 144-149, 2010 .

[9] K.W. Kase, J.T. Kase, "Clincal Therapeutic Applications of the Kinesio Taping Method. 3 ed," Albuquerque, NM: Kinesio IP; 2013.

[10] S.R. Freedman, L.T. Brody, M. Rosenthal, and J.C. Wise, "Short-term effects of patellar kinesio taping on pain and hop function in patients with patellofemoral pain syndrome," Sports Health, vol. 6(4), pp. 294300, 2014.

[11] S. Álvarez-Álvarez, F. San José, A.L. Rodríguez-Fernández, J. GüeitaRodríguez, and B.J. Waller, "Effects of Kinesio ${ }^{\circledR}$ Tape in low back muscle fatigue: Randomized, controlled, doubled-blinded clinical trial on healthy subjects," Journal of Back and Musculoskeletal Rehabilitation, vol. 27(2), pp. 203-212, 2014.

[12] D. Moher, A. Liberati, J. Tetzlaff, "Preferred reporting items for systematic reviews and meta-analyses: the PRISMA statement. Annals of internal medicine, vol. 151(4), pp. 264-269, 2009.

[13] S.J. Shultz, R.J. Schmitz, A. Benjaminse, M. Collins, K. Ford, A.S. Kulas, "ACL research retreat VII: an update on anterior cruciate ligament injury risk factor identification, screening, and prevention," J Athl Train vol. 50(10), pp. 1076-1093, 2015.

[14] A.M. Joseph, C.L. Collins, N.M. Henke, E.E. Yard, "A Multisport Epidemiologic Comparison of Anterior Cruciate Ligament Injuries in 
High School Athletics," Journal of Athletic Training, vol. 48(6), pp. 810-817, 2013.

[15] M.B. Johnsen, and M.H. Guddal, "Sport Participation and the Risk of Anterior Cruciate Ligament Reconstruction in Adolescents: A Population-based Prospective Cohort Study (The Young-HUNT Study)," Am J Sports Med, vol. 44(11), pp. 2917-2924, 2016.

[16] T.L. Sanders, H. Maradit Kremers, A.J. Bryan, D.R. Larson, D.L. Dahm, B.A. Levy, and A.J. Krych, "Incidence of Anterior Cruciate Ligament Tears and Reconstruction," Am J Sports Med, vol. 44(6), pp. 1502-1507, 2016.

[17] C. Turner, S. Crow, T. Crowther, and B. Keating, "Preventing noncontact ACL injuries in female athletes: What can we learn from dancers?," Physical Therapy in Sports, vol. 31, pp.1-8, 2018.

[18] K. Kase, J. Wallis, T. Kase, "Clinical Therapeutic Applications of the Kinesio Taping Method Book. 2nd ed," Ken Ikai Co Ltd: Tokyo, Japan; 2011.

[19] K. Kase, J. Wallis, and T. Kase, "Clinical Therapeutic Applications of the Kinesio Taping® Method,” Tokyo: Ken Ikai Co Ltd, 2003. 